\title{
The Application Progress and Prospect of Miniature Spectrometer in Precision Agriculture
}

\author{
Hui Zhi ${ }^{1}$, Jianrang Luo ${ }^{{ }^{*}}$, Ruiwen Liu ${ }^{2}$ \\ ${ }^{I}$ Northwest A \& F University, Xi'an, Shaanxi, China \\ ${ }^{2}$ Jiangsu Research and Development Center for Internet of Things, Intelligent Sensor Integration \\ Engineering Center, Wuxi, Jiangsu, China \\ *Corresponding Author.
}

\begin{abstract}
Miniature spectrometers are widely used in various fields such as industry and agriculture thanks to their advantages of easy portability, non-destructive testing, online testing, and high efficiency. By surveying massive research results at home and abroad, this paper summarizes the current development status of miniature near-infrared spectrometers at home and abroad, emphatically introduces the application research progress of miniature spectrometers in precision agriculture. Finally, it outlooks the development prospects of miniature spectrometers. While improving specificity, miniature spectrometers are developing towards high performance, new principles, and single chip.
\end{abstract}

Keywords: miniature spectrometer; soil nutrient; detection; precision agriculture; research progress

\section{Introduction}

Soil forms the basis of agricultural production, and soil nutrient is an important factor affecting the growth of crops. An important part of modern agriculture is to adjust the soil nutrient content to meet the nutrient requirements of crops at different growth and development stages. To adjust soil nutrients in real time, it is necessary to detect the dynamic changes of soil nutrients in real time, and fertilize appropriately according to soil nutrient information, thereby contributing to digital agriculture and precision agriculture, and increasing crop yields. Soil nutrient determination plays an important role in precision agriculture. The main soil nutrients nitrogen, phosphorus, potassium, etc. are important indicators for evaluating soil fertility. The content of nutrients such as nitrogen, phosphorus, and potassium greatly affects plant growth. In traditional soil nutrient testing, we usually need take the soil to be tested to the laboratory, and then perform detection using chemical analysis methods, which takes a long time, and consumes a lot of manpower, material and financial resources. Moreover, different nutrients require different measurement methods, so the operation is complicated and costly. When it comes to soil management in intelligent agriculture, considering timeliness, practicality and cost, chemical detection methods cannot meet the requirements. Therefore, fast, real-time and accurate acquisition of soil nutrient information is a key problem to be solved in modern precision agriculture.

Spectrometer is a precision instrument able to decompose polychromatic light into monochromatic light for collection and analysis. For its working principle, polychromatic light is reflected or transmitted by a substance, and then decomposed into a monochromatic spectral color band by the spectrometer. The color band already contains material element and content information. By analyzing the proportion of light of different wavelengths in the color band, it is possible to analyze the composition and content of the material ${ }^{[1,2,5]}$, which is a fast, non-destructive, simple measurement methods and green analysis detection technology supporting online operation. Spectrometer has the advantages of non-contact and non-destructive testing, high test accuracy, fast efficiency, online testing, and convenient secondary development, which is widely used in fields such as agriculture and forestry, remote sensing, metallurgy, geology, petroleum, chemical engineering, medicine, scientific research, military, etc. It displays more prominent advantages in applicability and reliability in terms of mass sample quality analysis, on-site quality analysis and engineering control analysis, which are incomparable by other analysis techniques $^{[1]}$. Spectrometer analysis technology supports quick detection of soil nutrients including nitrogen,

ISSN: 0010-8189 
phosphorus, potassium and organic matter content in the soil, so near-infrared spectroscopy detection technology enjoys extensive application prospects in precision agriculture technology. According to the different optical path structure, spectrometers can be divided into filter type, grating type, Fourier transform type, acousto-optic tunable filter type, and new micro-electromechanical system (MEMS)-based miniature spectrometers ${ }^{[2-4]}$.

MEMS miniature spectrometers adopt new MEMS devices to replace traditional spectroscopic optical paths and detectors, thus making the spectroscopy system more miniaturized and greatly broadening its application fields, which is a current research hotspot ${ }^{[3,5]}$. MEMS miniature spectrometer possesses unique advantages such as small size, light weight, fast speed, stable performance, low power consumption, easy integration, and suitability for harsh outdoor environments, making it show great application potential in real-time measurement and analysis in industry, agriculture, and forestry. According to the research report released by Research and Markets, the compound annual growth rate of miniature spectrometer reaches $11 \%$, and the market will reach 300 million US dollars in $2021^{[6]}$, so it has been studied by many domestic and foreign research teams ${ }^{[7-20]}$. At present, there are commercial high-performance MEMS spectrometers abroad, and some mid-low-end MEMS spectrometers have been developed in China for application in specific scenarios. However, it is still in the research and development stage domestically as a whole, and there is no high-performance MEMS spectrometer with high resolution, wide spectral range and high signal-to-noise ratio, which limits its application in many fields.

\section{Research Progress of Miniature Spectrometers}

Since 1990, micro spectroscopy systems have gradually appeared. At present, the most famous R\&D units are Ocean Optics of the United States and Avantes of the Netherlands. The two companies have developed a series of high-performance miniature spectrometers covering ultraviolet light, visible light, near-infrared light, mid-infrared light, etc. Taking into account the small size (only the size of a card) and high performance requirements, it is widely used in agriculture, medicine, environment, food fields as the benchmark in the field of miniature spectrometer products. As is Shown in Figure 1, is a typical miniature spectrometer developed by Ocean Optics and Avantes ${ }^{[21,22]}$.

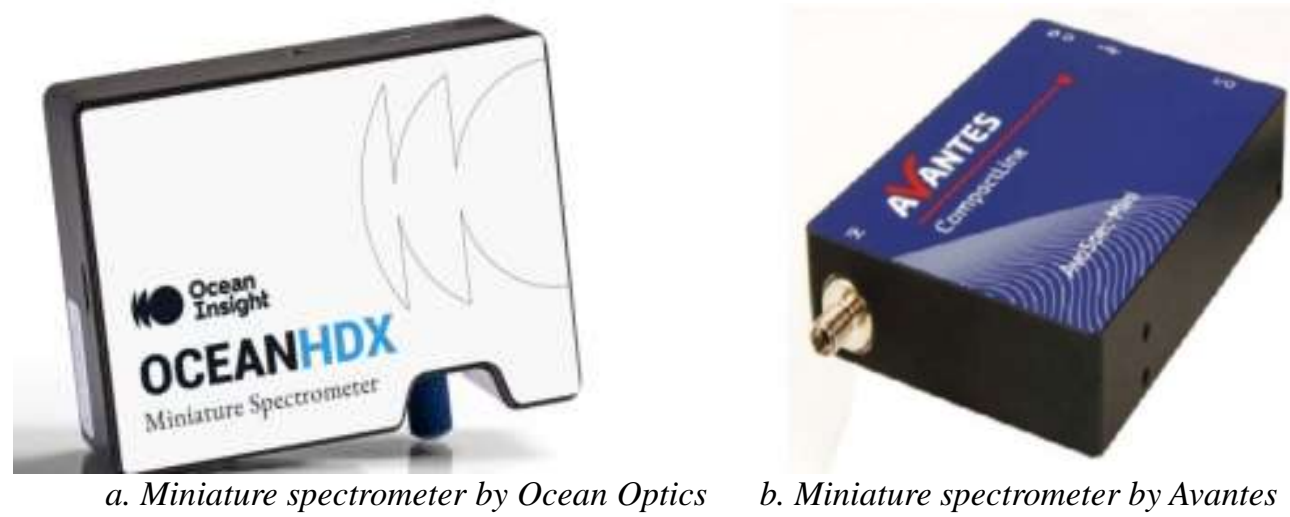

Fig 1: Physical image of miniature spectrometer

Japan's Hamamatsu Optical Co.Ltd. uses innovative technology to highly integrate the incident slit, secondary mirror, and detector into the same chip, and uses nanoimprint technology-based concave blazed gratings to produce finger-sized miniature spectrometer as shown in Figure 2. The spectrometer can be assembled to portable analytical instruments, drones with high restrictions on size and weight to achieve on-site, real-time testing ${ }^{[23,24]}$. 


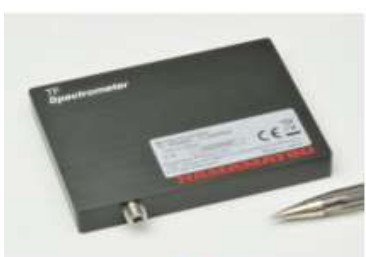

TF series

C13054MA/C13555MA

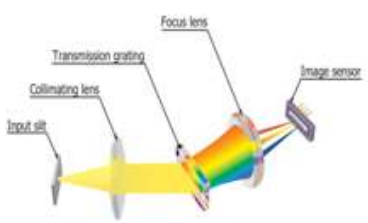

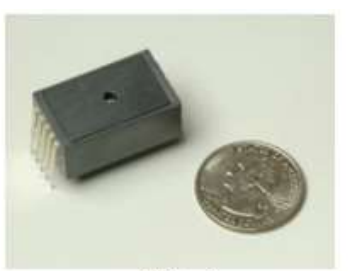

MS series MS series
C10988MA/C11708MA

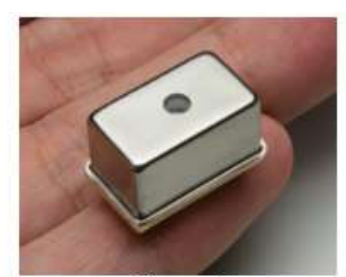

Micro series C12880MA/C12666MA

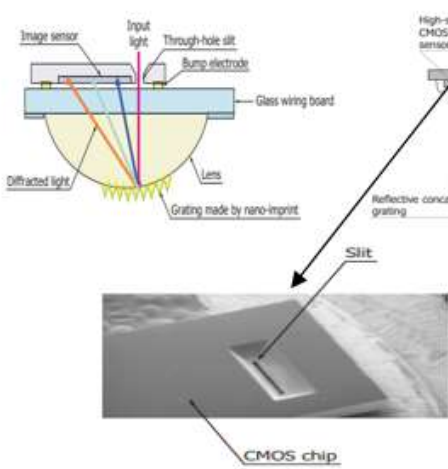

Fig2: The miniature spectrometer developed by Hamamatsu

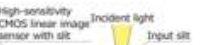
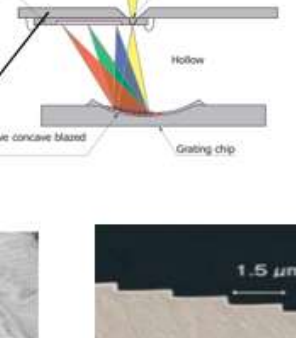

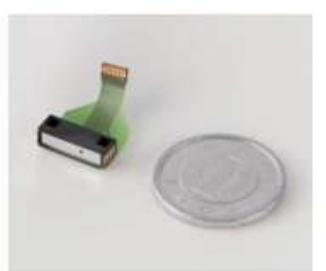

$\mathrm{SMD}$ series C14384MA
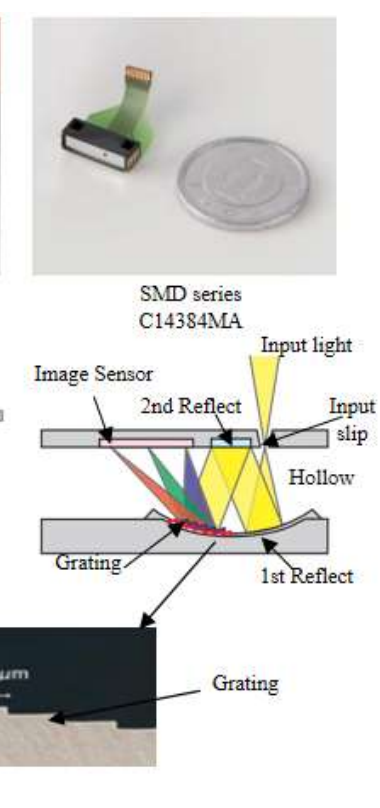
Polychromix in the United States, Honeywell Labs and MIT College have studied diffraction gratings-based miniature spectrometer with measurable wavelength in the range of 0.9 microns to 2.5 microns. With stable performance and no interior moving parts, it greatly eliminates the measurement error caused by movement of parts. Based on the modulation principle, Arizona State University, USA developed a micro thermal emission spectrometer based on Fourier transform; Texas Instruments developed a new micro imaging spectrometer using digital micro-mirrors as spectrum synthesis components; at the same time, Thermo Fisher of the United States, CID and $\mathrm{HACH}$, Fraunhofer Institute of Optical Microsystems of Germany, Astrophysics Laboratory of Joseph Fourier University, France, University of Nevada, Reno of USA, University of Florida, Neuchatel University of Switzerland, Delft University of Netherlands, Viavi Solutions (MicroNIR), TI, MicroParts, Brimrose have initiated the corresponding development of miniature spectrometers, with miniaturized and integrated spectrometers designed and developed ${ }^{[11-20]}$. Table 1 shows the research progress of miniature spectrometers in typical foreign companies.

Table 1 Research progress of foreign miniature spectrometers ${ }^{[11,12]}$

\begin{tabular}{|c|c|c|c|c|c|c|c|c|c|}
\hline $\begin{array}{l}\text { Manufactu } \\
\text { rer }\end{array}$ & Model & Technology & $\begin{array}{l}\text { Spectra } \\
\quad \text { I } \\
\text { resoluti } \\
\text { on }(\mathbf{n m}) \\
\end{array}$ & $\begin{array}{c}\text { Spectral } \\
\text { range } \\
(\mathbf{n m})\end{array}$ & $\begin{array}{l}\text { Detect } \\
\text { or }\end{array}$ & SNR & $\begin{array}{c}\text { Scan } \\
\text { rate/ } \\
\text { Integrati } \\
\text { on time }\end{array}$ & $\begin{array}{l}\text { Data transmission/ } \\
\text { Storage mode }\end{array}$ & $\begin{array}{c}\text { Weig } \\
\text { ht }\end{array}$ \\
\hline Stellar Inc. & $\begin{array}{l}\text { Red-Wave-M } \\
\text { icro }\end{array}$ & $\begin{array}{c}\text { MEMS } \\
\text { Fabry-Perot }\end{array}$ & 10 & $\begin{array}{c}175-215 \\
0\end{array}$ & $\begin{array}{c}\mathrm{InGa} \\
\text { As } \\
(1)\end{array}$ & $\begin{array}{l}5000: \\
1\end{array}$ & $\begin{array}{l}0.1-10 \mathrm{~m} \\
\mathrm{~s}\end{array}$ & USB & $\begin{array}{c}<125 \\
\mathrm{~g}\end{array}$ \\
\hline $\begin{array}{c}\text { RGB } \\
\text { Photonics }\end{array}$ & Q-Red & $\begin{array}{l}\text { Czemy-Tun } \\
\text { er Grating }\end{array}$ & 4 & $\begin{array}{c}900-170 \\
0\end{array}$ & $\begin{array}{l}\text { InGa } \\
\text { As } \\
(512)\end{array}$ & $x$ & $\begin{array}{c}7 \mathrm{~ms}-600 \\
\mathrm{~s}\end{array}$ & $\begin{array}{l}\text { USB,Bluetooth, } \\
\text { Proprietary }\end{array}$ & $160 \mathrm{~g}$ \\
\hline $\begin{array}{c}\text { Texas } \\
\text { Instrument } \\
\mathrm{s}\end{array}$ & Nano NIR & $\begin{array}{l}\text { Grating- } \\
\text { MEMS-D } \\
\text { MD }\end{array}$ & 10 & $\begin{array}{c}900-170 \\
0\end{array}$ & $\begin{array}{c}\text { InGa } \\
\text { As } \\
(1)\end{array}$ & $\begin{array}{c}6000: \\
1\end{array}$ & $0.3 \mathrm{~s}$ & $\begin{array}{l}\text { USB,Bluetooth/Me } \\
\text { mory micro-card }\end{array}$ & $85 \mathrm{~g}$ \\
\hline $\begin{array}{c}\text { Viavi } \\
\text { Solutions }\end{array}$ & $\begin{array}{l}\text { Micro NIR } \\
\text { Onsite }\end{array}$ & $\begin{array}{l}\text { LVF-Linear } \\
\text { Variable } \\
\text { Filter }\end{array}$ & $12-20$ & $\begin{array}{c}950-165 \\
0\end{array}$ & $\begin{array}{c}\mathrm{InGa} \\
\text { As } \\
(128)\end{array}$ & $\begin{array}{l}25000 \\
: 1\end{array}$ & $\begin{array}{l}0.25-0.5 \\
0 \mathrm{~s}\end{array}$ & USB & $100 \mathrm{~g}$ \\
\hline $\begin{array}{l}\text { Young } \\
\text { Green }\end{array}$ & NIR Scan & $\begin{array}{l}\text { MEMS-D } \\
\text { MD }\end{array}$ & 10 & $\begin{array}{c}900-170 \\
0\end{array}$ & $\begin{array}{l}\text { InGa } \\
\text { As } \\
(1)\end{array}$ & $\begin{array}{c}6000: \\
1\end{array}$ & $0.3 \mathrm{~s}$ & $\begin{array}{l}\text { USB,Bluetooth/Me } \\
\text { mory micro-card }\end{array}$ & $120 \mathrm{~g}$ \\
\hline Stratio & Link Square & $x$ & 10 & $\begin{array}{l}450-100 \\
0\end{array}$ & $x$ & $x$ & $x$ & $\mathrm{Wi}-\mathrm{Fi}$ & $57 \mathrm{~g}$ \\
\hline $\begin{array}{l}\text { Spectral } \\
\text { Evolution }\end{array}$ & LF-2500 & $\begin{array}{c}\text { Czerny-Tur } \\
\text { ner }\end{array}$ & $10-20$ & $\begin{array}{c}1000-25 \\
00\end{array}$ & $\begin{array}{l}\mathrm{InGa} \\
\mathrm{As} \\
(256)\end{array}$ & $\times$ & $\begin{array}{c}0.5-0.15 \\
\mathrm{~ms}\end{array}$ & USB,Bluetooth & $\begin{array}{c}1.5 \mathrm{k} \\
\mathrm{g}\end{array}$ \\
\hline IOR3 S.r.1 & Polispec NIR & $\begin{array}{l}\text { Concave } \\
\text { Grating }\end{array}$ & 2.2 & $\begin{array}{c}900-170 \\
0\end{array}$ & $\begin{array}{l}\text { InGa } \\
\text { AS } \\
(256)\end{array}$ & $x$ & $0.1-100 \mathrm{~s}$ & $\begin{array}{l}\text { USB,RS232, } \\
\text { Bluetooth }\end{array}$ & $\begin{array}{c}1.5 \mathrm{k} \\
\mathrm{g}\end{array}$ \\
\hline Brimrose & Luminar5030 & AOTF & $1-10$ & $\begin{array}{c}900-180 \\
0\end{array}$ & $\begin{array}{c}\text { InGa } \\
\text { As } \\
(1)\end{array}$ & $\begin{array}{c}3000: \\
1\end{array}$ & $\sim 5 \mathrm{~s}$ & TCP IP,I/O cable & $x$ \\
\hline $\begin{array}{l}\text { Thermo } \\
\text { Fisher } \\
\text { Scientific }\end{array}$ & Micro Phasir & $\begin{array}{l}\text { Grating- } \\
\text { MEMS } \\
\text { Hadamard }\end{array}$ & 11 & $\begin{array}{c}900-169 \\
0\end{array}$ & $\begin{array}{c}\mathrm{InGa} \\
\text { As } \\
(1)\end{array}$ & $x$ & $\sim 1 \mathrm{~s}$ & $\begin{array}{l}\text { USB/Internal } \\
\text { storage }\end{array}$ & $\begin{array}{c}1.25 \\
\mathrm{~kg}\end{array}$ \\
\hline Thorlabs & CCS175 & Grating & 0.8 & $\begin{array}{c}500-100 \\
0\end{array}$ & $\begin{array}{c}\text { CCK } \\
(3648 \\
)\end{array}$ & $\begin{array}{l}2000: \\
1\end{array}$ & $5 \mathrm{~ms}$ & USB & $400 \mathrm{~g}$ \\
\hline $\begin{array}{c}\text { Felix } \\
\text { Instrument } \\
\text { s }\end{array}$ & F750 & Grating & $8-13$ & $\begin{array}{c}310-110 \\
0\end{array}$ & $\begin{array}{l}\mathrm{Si}(25 \\
6)\end{array}$ & $x$ & $4-6 s$ & $\begin{array}{l}\text { Wi-Fi/Internal } \\
\text { storage }\end{array}$ & $\begin{array}{c}1.05 \\
\mathrm{~kg}\end{array}$ \\
\hline $\begin{array}{l}\text { Ocean } \\
\text { Optics }\end{array}$ & Flame NIR & Grating & $\sim 10$ & $\begin{array}{c}950-165 \\
0\end{array}$ & $\begin{array}{c}\mathrm{InGa} \\
\text { As } \\
(128)\end{array}$ & $\begin{array}{l}6000: \\
1\end{array}$ & $1 \mathrm{~ms}-60 \mathrm{~s}$ & USB & $265 \mathrm{~g}$ \\
\hline
\end{tabular}




\begin{tabular}{|c|c|c|c|c|c|c|c|c|c|}
\hline $\begin{array}{l}\text { Spectral } \\
\text { Engines }\end{array}$ & NIRONE2.0 & $\begin{array}{c}\text { MEMS } \\
\text { Fabry-Perot }\end{array}$ & $16-20$ & $\begin{array}{c}1550-19 \\
50\end{array}$ & $\begin{array}{c}\text { InGa } \\
\text { As } \\
(1)\end{array}$ & $\begin{array}{c}10000 \\
: 1\end{array}$ & $0.5 \mathrm{~s}$ & USB,Bluetooth & $15 \mathrm{~g}$ \\
\hline
\end{tabular}

Compared with foreign countries, China has a relatively late start in development of miniature spectrometers. The main research institutions include Shanghai Chenchang, Fuxiang Optics, Hangzhou brolight, Jingfei Technology, Wuxi Xunjieyuan Technology, Nanjing Zhongdi Instrument, Beijing Ruili Analytical Instrument, Tsinghua University, Shanghai Jiaotong University, Zhejiang University, Jinan University, Chongqing University, Changchun Institute of Optics, Fine Mechanics and Physics of Chinese Academy of Sciences and other companies, scientific research institutes of universities ${ }^{[2,8,29-32]}$. The miniature spectrometer developed by Hangzhou Jingfei Technology Co., Ltd. adopts the classic cross asymmetric C-T optical path structure for the spectroscopy module. With a size of merely a business card, it is very portable. By configuration of slits in different sizes, the optical resolution can reach $0.35 \mathrm{~nm}$, and the detection wavelength range is $200 \mathrm{~nm}-1100 \mathrm{~nm}$, the signal-to-noise ratio is greater than 300:1. The Changchun Institute of Optics, Fine Mechanics and Physics of the Chinese Academy of Sciences has developed a spatially modulated miniature spectrometer, which uses MOEMS multi-stage mirrors as the core device to achieve high-resolution and wide-spectrum detection. Chongqing University uses MEMS technology to develop the key component of the spectrometer-MOEMS scanning grating. Based on this, a scanning grating type miniature near-infrared spectrometer is developed ${ }^{[3]}$. A typical domestic miniature spectrometer is shown in Figure 4. The detectors in the spectrometer basically adopt imported CCD, CMOS, or InGaAs near-infrared detectors.
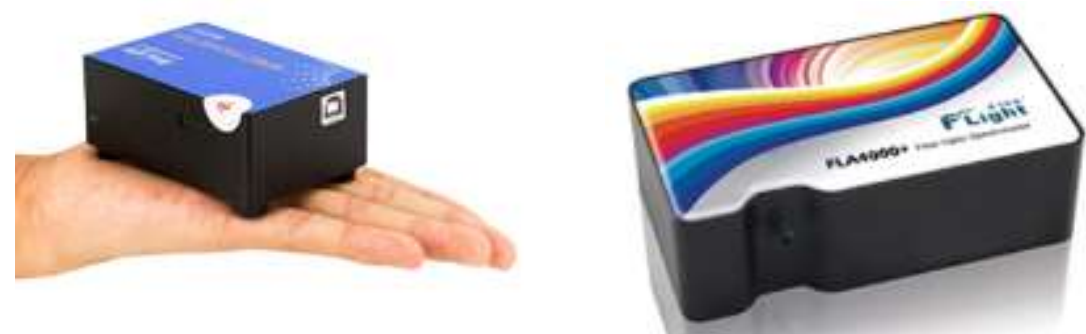

a. Spectrometer developed by brolights b. Spectrometer developed by Jingfei Technology
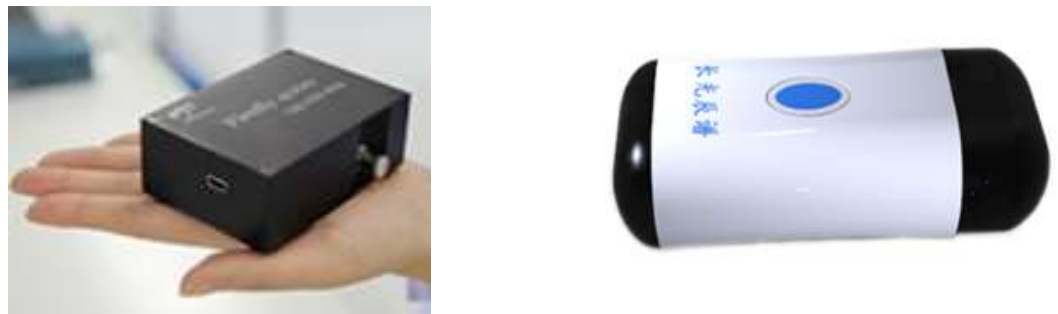

c. Spectrometer developed by Changchun Institute of Optics, Fine Mechanics and Physics, CAS

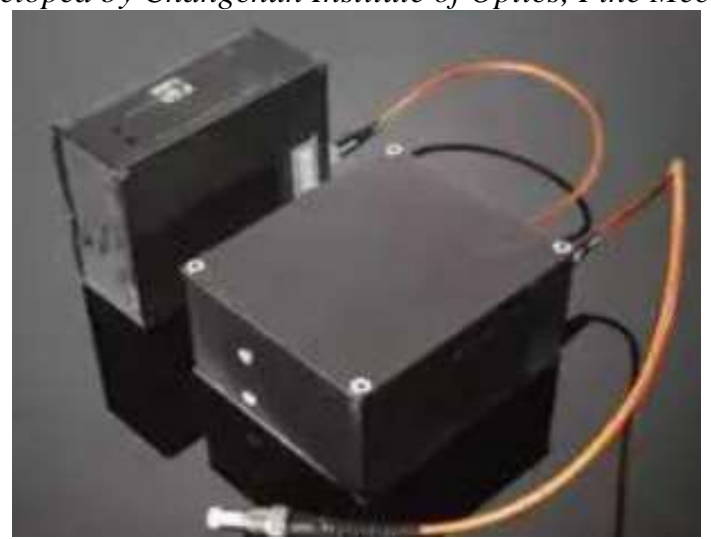

d. Miniature near-infrared spectrometer developed by Chongqing University

Fig 4: Physical image of typical domestic miniature spectrometers 
Researcher Zongyin Yang from Zhejiang University invented the technology for band gap control on a single nanowire. Special nanowires with gradually varied band gaps are used to replace the spectroscopic and detection elements in the traditional spectrometer. Through the chip manufacturing process, an array of light detectors is fabricated on nanowires. For light with different colors, various detectors can produce different responses, which marks the birth of the world's smallest spectrometer. The research paper "Single Nanowire Spectrometer" was published in the top international journal Science in $2019^{[33]}$.
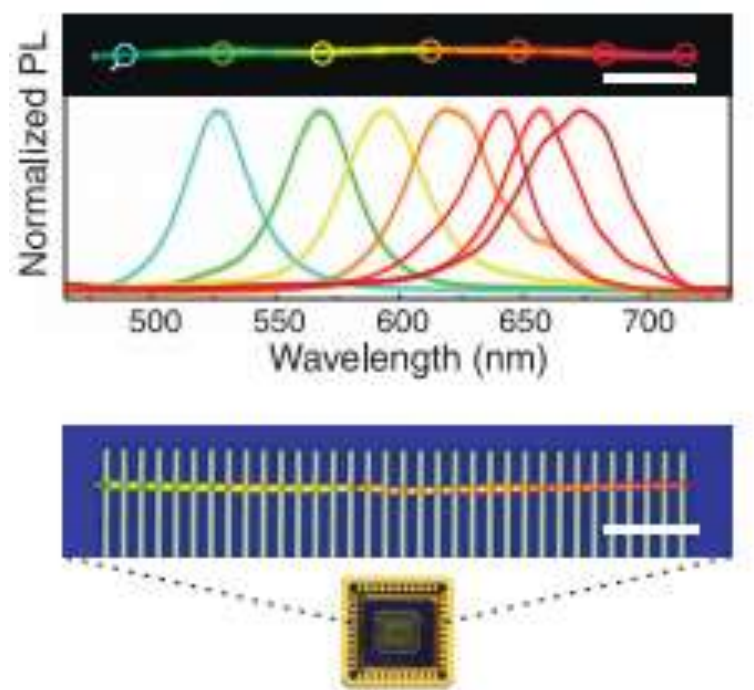

Fig5: Nanowire spectrometer developed by Zhejiang University

In addition, researchers from Tsinghua University and the Massachusetts Institute of Technology have developed a small and medium-sized spectrometer based on the principle of quantum dot technology. The Nanjing Geological Survey Center of China Geological Survey has successfully developed two types of micro-imaging spectrometers and achieved commercialization. In addition, Zhejiang University, Jinan University, Hefei University of Technology and other university research institutes have conducted research at different levels on optical dispersion modules and spectral correction technology ${ }^{[1-11,16-20]}$. Table 2 shows the research progress of typical domestic companies and scientific research institutes in miniature spectrometers.

Table 2 Research progress in domestic miniature spectrometers ${ }^{[11]}$

\begin{tabular}{|c|c|c|c|c|c|c|c|c|c|}
\hline $\begin{array}{l}\text { Manufactu } \\
\text { rer }\end{array}$ & Model & Technology & $\begin{array}{l}\text { Spectral } \\
\text { Resoluti } \\
\text { on (nm) }\end{array}$ & $\begin{array}{c}\text { Spectra } \\
1 \text { range } \\
(\mathrm{nm})\end{array}$ & $\begin{array}{l}\text { Detect } \\
\text { or }\end{array}$ & SNR & $\begin{array}{c}\text { Scan rate/ } \\
\text { Integration } \\
\text { time }\end{array}$ & $\begin{array}{c}\text { Data } \\
\text { transmissi } \\
\text { on/ } \\
\text { Storage } \\
\text { mode } \\
\end{array}$ & $\underset{\mathrm{m}^{3}}{\operatorname{dimension} / \mathrm{m}}$ \\
\hline $\begin{array}{l}\text { FuXiang } \\
\text { optics }\end{array}$ & $\begin{array}{l}\text { PG2000-P } \\
\text { ro }\end{array}$ & $\begin{array}{c}\text { Czerny-Tur } \\
\text { ner }\end{array}$ & 1.1 & $\begin{array}{c}200-11 \\
00\end{array}$ & $\begin{array}{c}64 \times 20 \\
48\end{array}$ & $800: 1$ & $10 \mathrm{~ms}-120 \mathrm{~s}$ & USB 2.0 & $157 \times 115 \times 41$ \\
\hline Zolix & 10420 & $x$ & 2 & $\begin{array}{c}200-10 \\
25\end{array}$ & 2048 & $\begin{array}{c}\text { 1300: } \\
1\end{array}$ & $1 \mathrm{~ms}-65 \mathrm{~s}$ & USB2.0 & $86 \times 110 \times 31$ \\
\hline Choptics & EQ2000 & $\begin{array}{l}\text { Czerny-Tur } \\
\text { ner }\end{array}$ & $0.2-7.6$ & $\begin{array}{c}200-11 \\
00\end{array}$ & 2048 & $400: 1$ & $1 \mathrm{~ms}-120 \mathrm{~s}$ & USB 2.0 & $x$ \\
\hline $\mathrm{CNI}$ & $\begin{array}{l}\text { Firefly } \\
4000\end{array}$ & $x$ & $<0.6$ & $\begin{array}{c}200-11 \\
00\end{array}$ & 3648 & $300: 1$ & $4 \mathrm{~ms}-10 \mathrm{~s}$ & USB2.0 & $89 \times 64 \times 36$ \\
\hline $\begin{array}{l}\text { TongShang } \\
\text { optics }\end{array}$ & EU2000 & $\begin{array}{c}\text { Czerny-Tur } \\
\text { ner }\end{array}$ & 1 & $\begin{array}{c}380-78 \\
0\end{array}$ & 2048 & $400: 1$ & $\begin{array}{c}3 \mathrm{~ms}-2000 \\
\mathrm{~ms}\end{array}$ & USB2.0 & $120 \times 89 \times 47$ \\
\hline
\end{tabular}

In summary, although domestic research and development on miniature spectrometer has achieved some gratifying

ISSN: 0010-8189

(C) CONVERTER 2020

www.converter-magazine.info 
results, there is still a big gap from foreign countries, and China is still in the key technology research and development stage as a whole. For example, with the support of the National Instruments project, Chongqing University, Zhejiang University, Changchun Institute of Optics, Fine Mechanics and Physics have achieved a series of progresses, but high-end products and core components still basically depend on imports. At the same time, there is insufficient development on original principle prototype and also insufficient research on new materials and single-chip spectrometers.

Recently, researcher Weiwei Cai from Shanghai Jiaotong University and Zongyin Yang from Zhejiang University, et al. published a review article "Miniaturization of optical spectrometers" in the top international journal Science. According to the working principle, the miniature optical spectrometers are divided into four categories, and the development history of miniature spectrometers in the past 30 years is systematically summarized, with detailed description given to their working principles, advantages and disadvantages, as shown in Figure $6^{[34]}$.
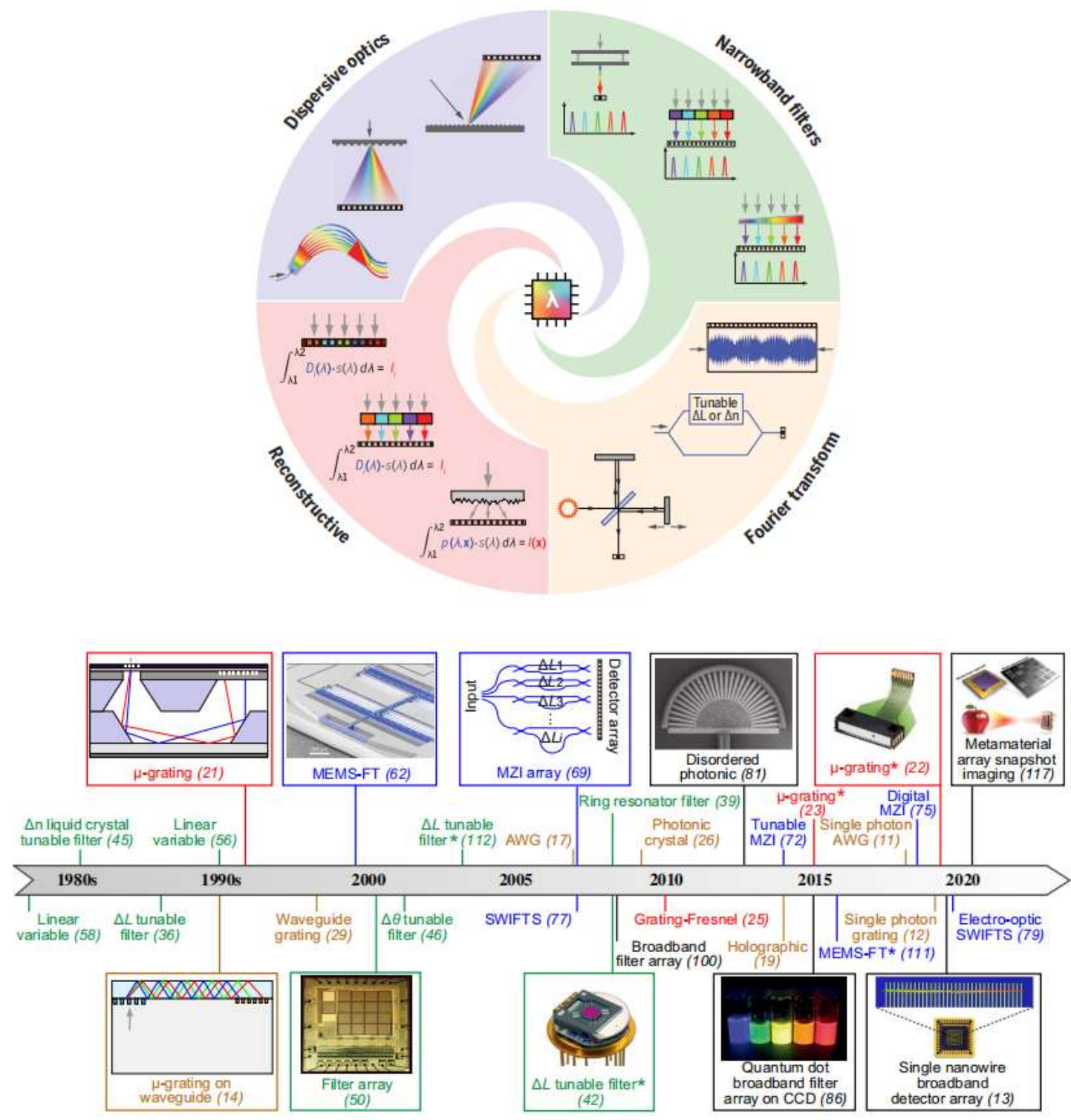

Fig6: Classification and development history of miniature spectrometers

\section{Research Progress of Miniature Infrared Spectrometers in Precision Agriculture Application}


Precision agriculture represents a new trend of development in the world today, which is a new type of agriculture that integrates information technology and agricultural production in an all-round way. Precision agriculture takes information technology as the support and implements a set of modern agricultural operation and management system based on spatial variation with fixed location, time and quantity ${ }^{[35]}$. Soil nutrient determination plays an important role in precision agriculture. By detecting the dynamic changes of soil nutrients in time, fertilizing reasonably according to nutrient information, and adjusting soil nutrients in real time, digital agriculture and precision agriculture wit higher crop yields are possible. Spectral analysis technology has great application prospects in precision agriculture technology. Through spectral technology, it is possible to detect soil nutrient information of nitrogen, phosphorus, potassium and organic matter content in time, understand the distribution of soil composition content in different areas, indirectly understand the growth status of crops, guide farmers to rational use of chemical fertilizers and improve land utilization.

So far, near-infrared spectrometers are still in the development stage in terms of instrument for soil composition detection, and there are not many portable ones supporting field applications. Researchers at Zhejiang University adopted portable short-wave near-infrared spectroscopy technology to detect the total nitrogen content of soil samples from farmland in Wencheng District, Zhejiang Province, and studied the effects of different soil scales on accuracy of the test model, concluding that sieved soil samples have higher test precision ${ }^{[36]}$. The team of Professor Dongjian He from Northwest A\&F University reviewed the basic principles of spectroscopic analysis for soil composition measurement, the development of instrument prototypes as well as the field experiment results, and highlighted the scientific issues that still need to be resolved ${ }^{[37]}$. Researchers from Shandong Academy of Sciences discussed the testing methods and applications of soil nutrients such as nitrogen, phosphorus, potassium, and carbon based on spectroscopy, used genetic algorithms to extract the characteristic wavelengths of soil nutrients, and established an analysis model using partial least squares to achieve accurate measurement of soil nutrients ${ }^{[38]}$. Based on the characteristic spectrum of total nitrogen and organic matter in soil samples in Northeast China, researchers from the Changchun Institute of Optics, Fine Mechanics and Physics of the Chinese Academy of Sciences developed a near-infrared spectroscopy measurement system with high signal-to-noise ratio dedicated to soil detection, whose predicted correlation coefficient exceeds $0.9^{[39]}$. In view of detection methods of water, organic matter, nitrogen, and inorganic elements in the soil, researchers at Changchun University of Science and Technology designed a near-infrared spectrometer optical system using a combination of dual-band coverage and composite astigmatism, and designed a near-infrared spectrometer optical system to meet the practical requirements of soil content detection ${ }^{[40]}$. Researchers from Huazhong Agricultural University used partial least squares regression to investigate the effect of particle size on the spectral prediction model of soil total nitrogen and organic carbon content ${ }^{[41]}$. Scholars from Northwest A\&F University used a portable spectrometer to study the relationship between the spectrum and farmland soil composition with Guanzhong loess soil as the research object. A mathematical model was established, the experimental model was optimized by comparing the spectral pretreatment methods, and a content detection model was established for soil organic matter, rapidly available phosphorus and available nitrogen ${ }^{[42]}$. Using visible and near-infrared spectroscopy techniques, Zhejiang University measured soil nutrient content based on chemometric methods, studied the spectral characterization mechanism and rapid acquisition method of soil total nitrogen, organic carbon, rapidly available phosphorus and available potassium information, and developed a set of portable soil nutrient rapid analysis system with a good human-machine interface ${ }^{[43]}$. The University of Electronic Science and Technology of China conducted research on the determination of total nitrogen in soil by near infrared spectroscopy, and established a regression prediction model based on the partial least square method ${ }^{[44]}$. Harbin University of Science and Technology used near-infrared spectroscopy to accurately detect soil nutrients online in real time, and studied several key technologies such as online detection instrument design, near-infrared sensor development, and spectral data processing methods in near-infrared detection of soil nutrients ${ }^{[45]}$. The Chinese Academy of Agricultural Mechanization Sciences took the typical cinnamon soil in the suburbs of Beijing as the research object, explored the feasibility of applying near-infrared spectroscopy analysis technology to quickly detect soil nutrients, studied and developed a set of soil near-infrared spectroscopy analysis system, and established a prediction model to meet the practical application test requirements ${ }^{[46]}$. 
In summary, seen from the recent research progress of spectroscopy in soil field application, it can not only analyze agricultural and soil organic component samples, but also analyze soil mineral components, predict soil texture, soil $\mathrm{pH}$ and so on. Therefore, near-infrared spectroscopy technology has great potential as a soil testing technology. The focus of soil nutrient detection based on spectral technology lies in secondary development of the spectrometer to achieve its specialization, which includes the following aspects: 1. Establishment of a soil nutrient database. Firstly, use conventional chemical analysis method to determine the content of organic matter, nitrogen, phosphorus, potassium, etc. of the sample to provide standard data for spectral prediction modeling. At the same time, collect the spectrum data of the sample to be tested by spectroscopy to establish a spectral database. 2 . Mathematical model establishment. Based on the relationship between soil nutrients and spectral characteristics, establish the correlation between spectral data and chemical test results, use multiple regression methods to establish a nutrient measurement model based on near-infrared spectroscopy, and calibrate the mathematical model of the sample to be tested by calibration. 3. Spectral preprocessing. Scattering interference, instrument noise, and interference caused by the absorption of other components to the component to be measured will affect the spectral data analysis as well as the analysis accuracy and stability of the calibration model. To establish a stable calibration model, acquire reliable, accurate characteristic wavelength, delete various interference noises, multivariate scattering correction of collected soil samples is beneficial to spectral preprocessing and calibration model establishment.

\section{Conclusion and Prospect}

Miniature spectrometers are widely used in many fields such as industry, agriculture, and forestry thanks to their advantages of easy portability, online non-destructive testing, and high efficiency. Through extensive investigations, this paper reviews the research progress of miniature spectrometers at home and abroad and their application progress in precision agriculture. Miniature near-infrared spectrometers are developing towards wide spectral range, high resolution, high signal-to-noise ratio, high integration, and single chip. At the same time, constant explorations and researches are made in new principles, new processes, and new materials. The development of micro-nano technology and optoelectronic technology is bound to provide strong technical support for the further miniaturization of spectrometers, enabling spectrometers to be integrated into electronic devices such as smart phones, drones, and wearables, realizing real-time monitoring of substances, and greatly expanding the spectrometer application scopes. In addition, formation of specialized spectrometer products through secondary development of miniature spectrometers is also an important development direction. Through the establishment of material spectrum databases, more accurate mathematical prediction models can be established based on big data technology to enable high-performance dedicated spectrometers, which shows huge application potential in various fields such as precision agriculture.

\section{Acknowledgements}

This paper is supported by a key project of Jiangsu Province (Project No. BE2019311).

\section{References}

[1] F. Q. Hu, S. Li, "Development of a portable near-infrared spectrometer based on MEMS technology," Instrumentation Technology, issue. 12, pp. 21-23, 2012.

[2] X. Y. Yu, Q. P. Lu, H. Z. Gao, et al., "Current status and prospects of portable pear-infrared spectroscopy instruments,” Spectroscopy and Spectral Analysis, vol. 33, no. 11, pp. 2983-2988, 2013.

[3] F. Yu, Q. Wen, H. J. Lei, et al, "Research progress in key technologies of miniature near-infrared spectrometers," Laser \& Optoelectronics Progress, vol. 55, pp. 100003, 2018.

[4] H. Ju, Y. H. Wu, "The development status of miniature spectrometers," Optics and Precision Engineering, vol. 9, no. 4, 2001.

[5] M. Xie, "Research on key technologies of near-infrared miniature spectrometer, master's thesis," University of Electronic Science and Technology of China, 2016. 
[6] "Instrument information network," Chemical Analysis and Meterage, vol. 26, issue. 4, 2017.

[7] Y. D. Wang, Y. H. Ma, S. B. Zhang, et al, "An integrated portable infrared spectrometer," Patent application number: CN201921469746.1.

[8] Y. Zhao, J. G. Lu, Y. X. Qin, et al., "Optimization design and experimental research of miniature Fourier transform spectrometer," China Optics, vol. 13, no. 2, pp. 412-424, 2020.

[9] S. H. Wang, X. Zhang, G. W. Zhang, et al., "Research progress in miniature near infrared spectrometer," Infrared Technology, vol. 42, no. 7, pp. 688-694, 2020.

[10] H. Zhong, "Design and analysis of miniature spectrometer with high resolution and wide spectral range," Laser \& Optoelectronics Progress, vol. 57, no. 15, pp. 153003-1-7, 2020.

[11] J. J. Mao, "Research on key technologies of visible light-near infrared miniature spectrometer, Master's thesis," University of Electronic Science and Technology of China, 2020.

[12] P. C, "Near infrared spectroscopy: A mature analytical technique with new perspectives-a review," Analytica Chinica Acta, vol. 1026, pp. 8-36, 2018.

[13] Z. Li, M. J. Deen, Q. Fang, et al., "Design of a flat field concave-grating-based micro-raman spectrometer for environmental applications," Appl. Opt, vol. 51, no. 28, pp. 6855-6863, 2012.

[14] U. Kc, J. A. Silver, D. C. Hovde, et al., "Improved multiple-pass Raman Spectrometer,” Appl. Opt, vol. 50, no. 24, pp. 4805-4816, 2011.

[15] G. Xia, B. Qu, P. Liu, et al., "Astigmatism-corrected miniature czerny-turner spectrometer with freeform cylindrical lens," Chin. Opt. Lett, vol. 10, no. 8, pp. 081201, 2012.

[16] B. Luo, "Research on the key technology of MOEMS scanning grating micromirror for Near-Infrared Miniature Spectrometer," PhD thesis, Chongqing University, 2012.

[17] G. Xia, "Design optimization and application of wide-band miniature spectrometer," PhD thesis, Zhejiang University, 2013.

[18] G. T. Xu, H. F. Yuan, W. Z. Lu, "Modern near infrared spectroscopy technology and application progress," Spectroscopy and Spectral Analysis, vol. 20, no. 2, pp. 142, 2000.

[19] J. X. Liu, X. H. Yin, S. H. Han, et al., "Research progress in portable near infrared spectrometer," Journal of Henan Agricultural University, vol. 53, no. 4, 2019.

[20] X. Q. Xu, G. Chen, H. Zhang, et al., "Development history and latest progress of near infrared spectrometer," Anhui Chemical Industry, vol. 43, no. 4, pp. 7-9, 2017.

[21] http://www.oceanoptics.cn/product/2363\#/-1/.

[22] http://www.avanteschina.com/Products-20302841.html.

[23] https://ibook.antpedia.com/212/n/75866-n.html.

[24] https://www.hamamatsu.com/jp/en/product/optical-sensors/spectrometers/index.html.

[25] http://www.elecfans.com/d/1237761.html.

[26] https://senorics.com/hardware/.

[27] https://www.xianjichina.com/special/detail_368276.html.

[28] https://www.si-ware.com/how-it-works/mems-ft-ir/.

[29] https://www.brolight.cn/Mini_Spectrometer.html.

[30] http://www.lcdfly.com/product-wxgq/.

[31] http://www.cnilaser.com/C-spectrometer.htm.

[32] https://www.championoptics.com/product/78.

[33] Z. Y. Yang, A. O. Tom, et al., "Single-nanowire spectrometers," Science 365, pp. 1017-1020, 2019.

[34] Z. Y. Yang, et al., "Miniaturization of optical spectrometers," Science 371, 480, 2021.

[35] J. T. Liu et al., "Introduction to precision agriculture,” Meteorological Press, 2002.

[36] H. L. Zhang, Y. He, "Portable shortwave near-infrared spectroscopy instrument to detect soil total nitrogen content," Spectroscopy and Spectral Analysis, vol. 36, no. 1, pp. 91-95, 2016.

[37] D. J. He, C. H. Yang, et al., "Research progress in real-time determination of farmland soil composition in precision agriculture," Transactions of the Chinese Society of Agricultural Engineering, vol. 28, no.7, 2012.

[38] X. Y. Li, P. P. Fan, et al., "Rapid detection of soil nutrients by visible-near infrared spectroscopy," Spectroscopy and Spectral Analysis, vol. 37, no. 11, pp. 3562-3566, 2017. 
[39] H. Z. Gao, Q. P. Lu, "Near-infrared spectroscopy analysis and measurement system for soil main nutrients," Spectroscopy and Spectral Analysis, vol. 31, no. 5, pp. 1245-1249, 2011.

[40] Q. Xin, Y. An, et al., "Analysis and design of near infrared spectrometer for soil content detection," Journal of Changchun University of Science and Technology (Natural Science Edition), vol. 41, no. 5, 2018.

[41] S. Li, "Prediction of soil carbon and nitrogen based on Vis/NIR spectroscopy under different particle sizes," Master's thesis, Huazhong Agricultural University, 2010.

[42] X. Chen, "Research on the determination method for farmland soil nutrients based on spectral analysis," Master's thesis, Northwest A\&F University, 2015.

[43] S. Y. Jia, "Research on soil nutrient detection method and instrument based on spectral analysis technology," PhD thesis, Zhejiang University, 2015.

[44] Z. Liu, "Research on soil total nitrogen detection method based on visible infrared spectroscopy technology," Master's thesis, University of Electronic Science and Technology of China, 2020.

[45] X. Y. Yu, "On-line real-time detection system and its key technology for near-infrared soil nutrient content," PhD thesis, Harbin University of Science and Technology, 2015.

[46] J. Li, "Development and experimental research of near infrared spectroscopy fast analysis system for soil nutrients,” Master's thesis, Chinese Academy of Agricultural Mechanization Sciences, 2011. 